\title{
Can scenic indicators help sustain Fraser Hill's healthy ecosystems?
}

\author{
O. Jamilah, A. K. Nur Emira \& R. A. R. Nur Fatin \\ Department of Landscape Architecture, \\ Kulliyyah of Architecture \& Environmental Design, \\ International Islamic University, Malaysia
}

\begin{abstract}
The ecological landscape is among the factors that may implicate tourists' visitations to a nature-based landscape of the highland environment. It is found that the natural beauty of certain natural resources makes a significant contribution to the development of nature-based tourism. Sustainable landscape management could be essential to continuously maintaining the rich biodiversity of an ecosystem. This study assesses the correlation of the scenic beauty of Fraser's Hill to its ecological landscapes. The natural heritage of Fraser's hill can be identified through its unique ecosystems (e.g. forest, waterfall and lake) that house varieties of flora and fauna. This study adopted the perception-based paradigm, in which the public were the respondents. The necessary data was collected using: 1) a photographic questionnaire survey (non-locals public); 2) a questionnaire survey (in situ tourists). Previous to this, an exploratory field observation (EFO) was carried out on site to determine the potential ecological attributes of the area. The results of the questionnaire survey show that the ecological attributes (e.g. hilly landform, greenery and water elements) have implicated the scenic beauty of Fraser's Hill. Similarly, the results obtained from the second method agree that the ecosystems (e.g. lake and water fall) with ecological attributes are most preferred. Findings show that there is a high agreement on the scenic beauty of the natural and historical heritage. The insights provide quantitative information that may implicate the sustainability of a highland environment, highland best management practices, local authorities, the economic value, the tourism industry and many more. Most importantly, the findings suggest that scenic beauty can be an indicator of a healthy ecosystem that may further sustain other sensitive environments of Malaysia.

Keywords: sustained, healthy ecosystems, scenic indicator, highland environment.
\end{abstract}




\section{Introduction}

It is observed that healthy ecosystems of highland environments may influence nature-based tourism. This is true when they provide good recreational and leisure experiences (de Groot et al. [1]). A healthy ecosystem can be explained as the ability to function naturally and sustain the rich biodiversity within its environment. In many cases, pleasant scenery can be associated with ecological landscapes. So, the strength of an ecologically healthy ecosystem is about being able to retain beauty or aesthetics of a landscape (Bell [2]). This explains that scenic beauty can be an indicator to determine the quality of an ecosystem. A review by Daniel and Boster [3] states that scenic beauty of a landscape is among the most important elements of natural resources. The authors further claim that beauty is not only partially defined by certain characteristics of an environment, but it also depends upon human's judgment. In this case, public's assessment becomes crucial under the perception-based paradigm.

In relation to that, this study assessed the correlation of scenic beauty of Fraser's Hill to its ecological landscapes. It is one of the most significant naturebased hill stations of Malaysia that has long been known for its rich bio-diversity. Fraser's Hill is unique in the sense that it houses several distinguished flora and fauna. It is a proud natural heritage recognised as one of the most biologically diverse ecosystems of the world. Fraser's Hill is situated above sea-level at approximately between $1000 \mathrm{~m}$ to $1525 \mathrm{~m}$. Due to this geographical character, the hill has experienced nice climate with the temperature between $17^{\circ} \mathrm{C}$ to $25^{\circ} \mathrm{C}$. During the British occupation, it was a popular hill retreat among their officials. Not until 1922, the hill station was opened to public's visitation. Since then, it has received high number of tourists' visitations. Perhaps, this is due to its sustainable natural resources, namely scenic landscapes and cool climate.

In the context of Malaysia, more scenic assessment studies are needed in order to determine the condition of certain landscapes in relation to natural resources and ecosystems. The insights may help identifying sustainable landscape management practices, environmental policy, or preservation of ecosystems with significance ecology. Future research should have more concerned for proper, strict criteria, precision, reliable, and valid assessment techniques, so that, the biological, economical and legal aspects of the environmental management criteria are well established (Daniel [4]). It is anticipated that knowledge learnt from the study can be used for best practices of ecological management. This would help sustaining the nature-based landscapes, whose scenic and ecological values have tourism implication.

\section{Scenic assessment and indicator}

Scenic assessment is a method used to measure beauty or quality of a landscape, where landscape is referring to the natural scenery of an environment with some visible features such as greenery, water elements or undulating landform. The beauty appeal of a landscape can be measured using two methods; expert and perception-based (public) paradigms. The expert-based translates the biophysical 
features of a landscape into a formal design parameter that is measured using line, form, unity, variety, colour, textures or shape. These are the art and design vocabularies accepted to be the universal indicators to determine the landscape quality or value. On the other hand, the public-based treats the biophysical features of a landscape as the stimulus to detect or stimulate a physical reaction of scenic value. Such reaction is referring to the state of making scenic preference through one's sensory judgements. They are perceptual assessments having incorporated human external stimuli that are explained through vision or sight. For example, the exercise guides an observer to judge and rank the landscape quality using photographs as the surrogates. Jamilah and Nur Syazwani [5] provide simple explanation on the approach of each paradigm. In general, both paradigms imply similar philosophy that the utilitarian aspect of the assessed landscape is not an issue.

This study adopted the perception-based assessment with the understanding that nature-based environment is a public's landscape. Thus, people's interests, expectations, participation and desires would be relevant to identify the conditions of the ecosystems. It is evidenced that the relationship between ecology and scenic beauty may affect the landscape planning, design and management (Gobster et al. [6]). The author and his associates also point out that landscapes that are perceived as aesthetically pleasing are more likely to be appreciated and protected than the landscape that has no aesthetics value. Thus, by assessing the scenic preferences of the nature-based landscapes, perhaps their ecological significance can be more appreciated, due to their known function and values. The results of the assessment are considered important, since it helps sustaining people's landscapes with high ecological implication. Thus, the scenic quality of an environment can be an indicator to guide and plan for better management of public ecological landscapes. The results would be recommendations or guidelines on how to manage and protect the sensitive environment that are preferred by the people.

Though there have been many studies done on the nature-based environments (Kaplan and Kaplan [7]), insight on scenic as an indicator to healthy ecosystems is still in demand. It is understood that ecology, landscape, ecosystem and natural environment are all nature concerns. A review by Odum [8] indicates that scenic landscape is among the ecological values that affects human perception and wellbeing, planning and management, conservation and preservation of sensitive ecosystems. In short, scenic beauty can be defined as a view that pleases one's eyes, while natural scenery is referring to nature or to the state of being naturalness. Interestingly, nature is seldom associated with the unpleasant sceneries. Perhaps, this further explains that there is a connection between ecology and scenic beauty.

Identification of high ecological landscapes using scenic assessment is considered important in attempt to sustain significant ecosystems such as highland environment. Here, the use of scenic indicator would be the relevant technique to determine an environmental condition. Similarly, Anderson [9] points out that scenic value can be accepted as the primary indicator of an intrinsic landscape. The author claims that such value has the potential to evoke the positive responses in people. Measuring scenic conditions through the richness of natural elements 
such as landforms (undulating topography), water (lake, river or waterfall), and vegetation (greenery or lush of trees) of a landscape is among the approaches of scenic assessment. This explains that healthy condition of an ecosystem can be related to the degrees of scenic integrity (Galliano and Loeffler [10]). Besides that, others visible elements such as land use patterns and culture are observed to influence the quality of a landscape as well. They are the secondary factors that may relate to the aspects of history and heritage and have potential to implicate the image and sense of a landscape.

\section{Background of study area}

Fraser's Hill is the only hill station in the country that has undergone a very mild change of land use and development (Kiew [11]). The development of the hill station is limited and restricted, due to its natural setting and lack of flat land. Among the hill stations, Fraser's Hill displays the most colonial charm with the ambience of the English old stone bungalows (Knopf [12]). This picturesque scenery reflects the architecture style of the Tudor. Many remained buildings of the colonial such as resorts, inns, private bungalows, and government officials have architectural heritage implication. They are magnificent structures resembled the old British houses and villages of the late $19^{\text {th }}$ century architecture. It is observed that the heritage provides significant visual experience to tourists. Interestingly, tourists visiting Fraser's Hill may not experience such landscape scene at any other hill stations of the Peninsula. This further suggests that the architectural heritage of the hill has high potential to influence the tourism industry of the state of Pahang.

Fraser's Hill houses diversity of bird species. The hill has become the route to thousands of bird migration. Due to that, it serves as one of the major bird sanctuaries in this region. Here, a bird watching tournament is annually organised in June and the recreational activity invites many bird lovers all around the world. The present natural landscapes with healthy ecosystems are seen to continuously support and sustain the migration of birds to this side of the world. So, this shows that the nature-based recreational activity can be a factor that would attract more tourists to the hill station. Another recreational activity of the hill found to be important is playing golf. The land use captures nice ambience with its hilly and greenery forest at the background. After Malaysia gained its independence, similar land use planning has been adopted with the understanding that natural and historical heritage are the priceless assets of the hill station.

Scenic beauty of Fraser's Hill and its unique ecosystems are the reasons why the site was selected for the study. The hill consists remarkable ecosystems with predominantly natural appearance of spectacular mountain rainforest views. The mountain forest is also known as the upper hill dipterocarp forest. There are a number of tall dipterocarp trees that dominate the forest canopy. The trees are mostly originated from the species of Shorea platyclados. Besides that, they are plants with various colours and shapes of foliage, heights and sizes. It is evidenced that the diverse flora species have also contributed to awesome landscape scenes. The combination of these floras makes the rain forest ecosystem 
as one of the kind that captivates ones' eyes with visual excitement. It is observed that the natural landscape elements of the undulating landforms and valleys may also implicate the scenic beauty of Fraser's Hill. The water features coming from both waterfall and lake ecosystems have also signified the hill visual impact. Perhaps, this describes the importance of Fraser's Hill as the nature-based landscape to the country.

\section{Research methodologies}

The necessary data were obtained from these methods; i) exploratory field observations, ii) photographic questionnaire survey and iii) questionnaire survey. The non-locals respondents were asked to rank the scenic landscapes in correlation to the ecological attributes of Fraser's Hill using photographic questionnaire survey. On the other hand, the in-situ tourists were asked to rate the scenic preference statements using the questionnaire survey of 5-point Likert Scale. Before that, the experts were asked to classify the ecological attributes from a pool of coloured photographs. The exercise helped reducing the issue of biasness, when the classification was not done by the researchers themselves. The followings describe the procedures used in the methods employed.

\subsection{Exploratory field observation (EFO)}

The main objective of the exploratory field observation (EFO) was to identify the ecological attributes that might influence the scenic beauty of Fraser's Hill. Photographs of the relevant landscape scenes were taken during the day times because to maintain the exact appearance of the landscapes depicted. Photographs were used as surrogates to real site and thus, colour, form, and texture of an object could be clearly evidenced under enough sunlight. During the EFO, some data concerning tourists' popular visitation spots that related to the ecological attributes were also identified. The EFO exercise was carried out for two days; starting from the $1^{\text {st }}$ to $2^{\text {nd }}$ March 2014 . The locations were randomly picked, where more priorities were given to the spots that often frequented by tourists. All the landscapes were depicted using a Samsung Digital Smart Wifi WB25OF camera. The approach to the EFO is necessary, since it provides a comprehensive perspective about the real situation on site (Babbie, 1979). The objectives of the EFO are as follows:

i) To identify the ecological attributes that might implicate public's scenic beauty preferences.

ii) To take photographs for the preparation of survey instruments.

iii) To identify the popular spots that receive high tourists' visitations.

\subsection{Survey questionnaire: rating evaluation}

The objective of the questionnaire survey was to identify the public's scenic preferences for ecological landscapes of Fraser's Hill. It was a closed ended instrument with a targeted group of both local and international tourists. Though the sample (33 numbers) size was small, the result can be accepted significant in 
understanding the subject studied. The two days survey $\left(8^{\text {th }}\right.$ to $9^{\text {th }}$ March 2014) was purposely conducted on weekend, due to high crowds of tourists identified during the EFO exercise. The format of the questionnaire survey consisted of four sections. Section 1 asked the respondents to state their demographic and social backgrounds. The respondents were asked to state their gender, age, place of origin, level of education, occupation and income. Section 2, 3, and 4 of the survey asked the tourists to state their preferences for several landscape scenes of Fraser's Hill. Each of the sections consisted of sentences describing the feeling and the judgment of the respondents on scenic beauty. The respondents rated their agreement or disagreement to the given statements by choosing a number with a graded response. The questions were designed based on the five points Likertscale; $(1$ = strongly disagree; 2 = disagree; 3 = neutral; 4 = agree; and $5=$ strongly agree).

\subsection{Photographic survey questionnaire: ranking evaluation}

The photographic survey was designed to assess the scenic preferences of the respondents of the non-locals public. The variables (refer to Table 1) used in the assessment consisted of ecological (view 1 , view 3, view 4, view 5 , view 6 and view 7) and architectural heritage attributes (view 2, view 8 and view 9). Before that a pool of photographs with the total of 50 landscape scenes were shown to the expert for the classification exercise. Only 9 photographs were selected for the ranking purpose, while the rest were discarded, due to the issues of quality, redundancy and irrelevancy of images. The photographic questionnaire survey was separately conducted at two provinces in the Klang Valley; e.g. Gombak and Kuala Lumpur. Both Gombak and Kuala Lumpur are part of the cities and towns are bordering the state of Selangor. Due to time constraint and potential of getting good crowds, The Kuala Lumpur City Centre (KLCC) park (25 respondents) and the campus of International Islamic University, Malaysia, (IIUM), Gombak (18 respondents) were picked as survey sites. The respondents were asked to rank the nine photographs shown. Rank 1 indicated the most preferred scene, while rank 9 was the least preferred. Besides that, the survey also asked the respondents to state their demographic information such as gender, age, place of origin, marital status, level of education occupation/employment status, and income.

\section{Results and findings}

The results and findings were based on the two methods of data collections as described earlier; photographic questionnaire survey and questionnaire survey. The followings describe the details of the results.

\subsection{Photographic questionnaire survey}

Table 2 presents the results of scenic preferences of Fraser's Hill using photographic questionnaire survey. The overall rankings show that four (4) views have similar score (2\%), which is at rank 6 (e.g. View 3, View 4, View 5 and 
Table 1: List of photographs used to assess scenic beauty preferences of public non-locals.

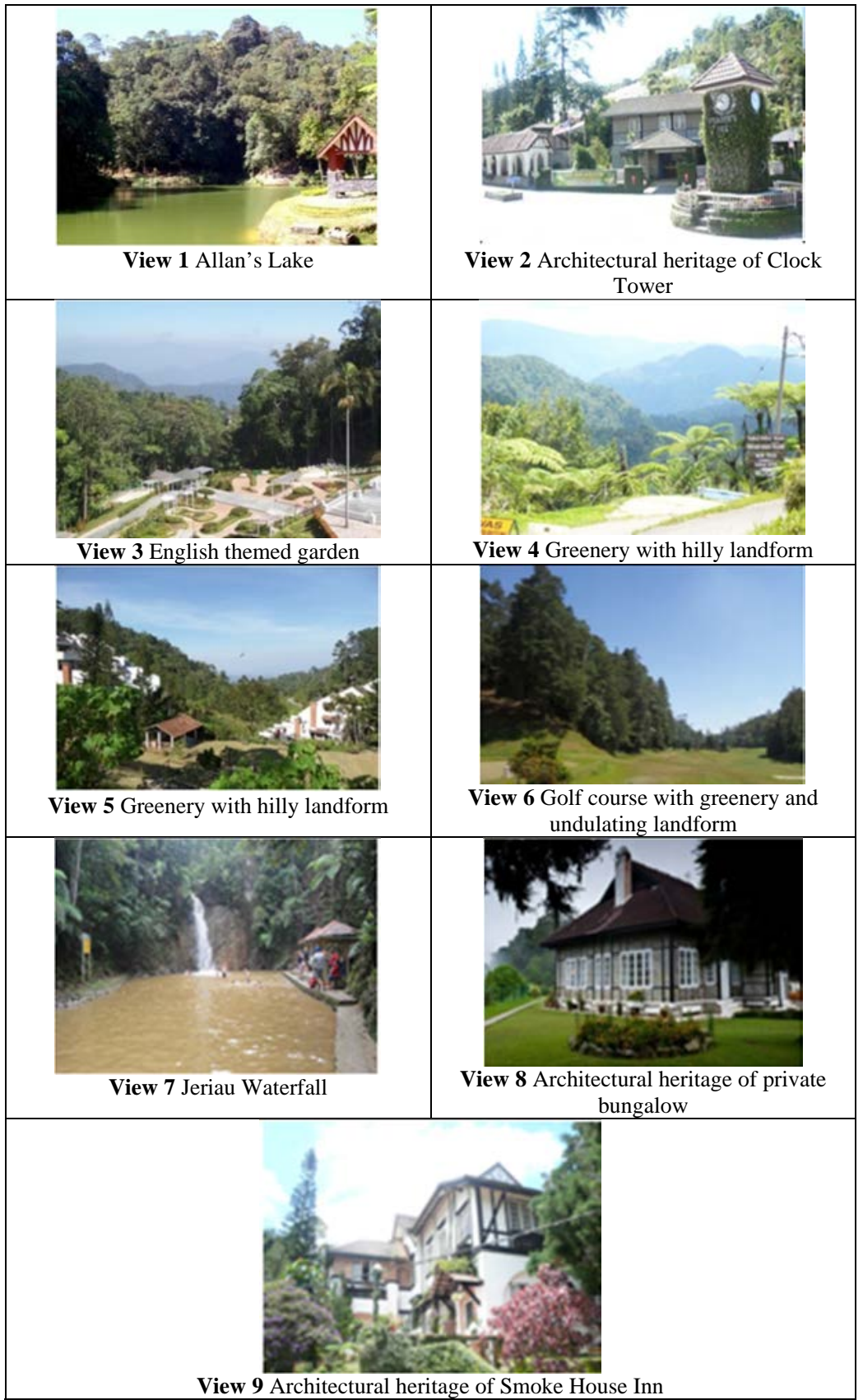


Table 2: Results of photographic questionnaire survey rated by non-local public.

\begin{tabular}{|l|c|c|l|}
\hline \multicolumn{1}{|c|}{ Landscape sceneries } & Ranking & $\mathbf{( \% )}$ & \multicolumn{1}{|c|}{ Remark } \\
\hline View 1 (Lake) & $\mathbf{1}$ & $\mathbf{4 0}$ & $\mathbf{1}^{\text {st }}$ highest scores \\
\hline View 2 (Architectural heritage - Clock Tower) & 5 & 3 & $1^{\text {st }}$ lowest scores \\
\hline View 3 (Themed garden) & 6 & 2 & Lowest scores \\
\hline View 4 (Greenery + hilly landform) & 6 & 2 & Lowest scores \\
\hline View 5 (Greenery + hilly landform) & 6 & 2 & Lowest scores \\
\hline View 6 (Golf course + greenery + hilly Landform) & 4 & 5 & $2^{\text {nd }}$ lowest scores \\
\hline View 7 (Waterfall) & 3 & 7 & Average scores \\
\hline View 8 (Architectural heritage - Bungalow) & $\mathbf{2}$ & $\mathbf{3 7}$ & $\mathbf{2}^{\text {nd }}$ highest scores \\
\hline View 9 (Architectural heritage - Smoke House Inn) & 6 & 2 & Lowest scores \\
\hline TOTAL & & 100 & \\
\hline
\end{tabular}

View 9). The top two most preferred landscape sceneries are View 1 (Rank 1: 40\%) and View 8 (Rank 2: 37\%), while both View 7 (Rank 3: 7\%) and View 6 (Rank 4: 5\%) can be accepted as the moderate preferred sceneries. So, the least preferred landscapes can be directed to View 2 (Rank 5: 3\%), View 3 (Rank 6: 2\%), View 4 (Rank 6: 2\%), View 5 (Rank 6: 2\%), and View 9 (Rank 6:2\%). However, the result peculiarly indicates that there is high variance in the scores between the most preferred and the least preferred sceneries. Secondly, between assigned in each photograph. For instance, the most preferred scenery (view 1) presented the ecological attribute, while the second most preferred scenery (view 8) represented the architectural heritage attribute. In conclusion, the findings suggest that the majority of the respondents were favoured for both nature-based and architectural heritage landscapes. It is also found that the most preferred landscape scene (View 1) contains high ecological attributes, namely greenery and water feature. Finding concludes that the most preferred landscape scene of the non-local public is related to nature-based landscape.

\subsection{Questionnaire survey}

Demographic findings show that about $80 \%$ (26 peoples) of the tourists were locals, while the remains were foreigners. The information on the gender, age, origin, education, income and occupation of the respondents provide general information on the characteristics and pattern of tourists visiting Fraser's Hill. The result further shows that high number of the tourists (26: 79\%) enjoyed visiting the hill station. Interestingly, high number of them (23: 70\%) visited the hill, due to its nature-based landscapes. High number of the tourists agreed (23:70\%) that the landscapes of Fraser's Hill are beautiful.

In general, results on the relationship of scenic beauty to ecological attributes show that high number of tourists (24: 73\%) agreed that the landform of Fraser's Hill is beautiful, while more than half (19: 58\%) agreed that the view of the waterfall is beautiful. Further, more than half (17: 52\%) of the tourists agreed that the view of lake is beautiful. However, it is found that among these, waterfall receives the highest disagreement $(7: 21 \%)$ on scenic quality as compared to the rest; e.g. landform (1:3\%) and lake (1:3\%). In summary, the preliminary insights suggest that scenic beauty has significant correlation to landform, waterfall and 
lake. Further, it was expected that the tourists would appreciate the architectural heritage scenery. Importantly, the result shows that the highest number (28: 85\%) of tourists liked the scenery. Table 3 summarizes the overall findings.

Table 3: Summary of results between photographic questionnaire survey and questionnaire survey.

\begin{tabular}{|l|l|}
\hline \multicolumn{1}{|c|}{ Photographic questionnaire survey } & \multicolumn{1}{c|}{ Questionnaire survey } \\
\hline Rank 1: Ecology (Lake) & Agreement (85\%): Arch. heritage \\
\hline Rank 2: Arch. heritage (Bungalow) & Agreement (73\%): Ecology (landform) \\
\hline Rank 3: Ecology (waterfall) & Agreement ( 58\%): Ecology (waterfall) \\
\hline Rank 4: Ecology + man-made (golf course) & Agreement (52\%): Ecology (lake) \\
\hline Rank 5: Arch. heritage (Clock Tower) & Disagreement (21\%): Ecology (waterfall) \\
\hline $\begin{array}{l}\text { Rank 6: Ecology + man-made (themed garden); } \\
\text { ecology + man-made (forest), ecology + man- } \\
\text { made (forest) and arch. heritage (inn) }\end{array}$ & $\begin{array}{l}\text { Disagreement (3\%): Ecology (landform) and } \\
\text { ecology (lake) }\end{array}$ \\
\hline
\end{tabular}

In conclusion, both ecological and architectural heritage attributes have significantly correlated to scenic beauty of the hill. Nevertheless, there are some factors observed to influence the overall results of the study. For instance:

i) Photographic composition of several views should not depict an object and human scale assumed to negatively influence the scenic preferences of the respondents. For instance, the lighting pole shown in View 3 and View 4 is among the man-made element assumed to lead to low ranking score.

ii) The scenery of waterfall received $21 \%$ of scenic disagreement. The score can be considered significant, due to the issue of high rejection. During the EFO, it was found that there is an artificial pond built around the waterfall. Perhaps, this man-made construction had influenced the naturalness of the waterfall. Though more than half of the in situ tourists agreed that the view is beautiful, almost $1 / 4$ of them also agreed that the view is not beautiful.

iii) It was anticipated that the architectural heritage of the Smoke House Inn, presented in View 9 would receive high ranking score. However, the view is among the least preferred. Again, the issue of composition might have influenced the respondents' scenic judgment. Perhaps, the image of the Inn should not get blocked by the shrubs. The form and design motif of the Inn was not effectively depicted in the photograph and perhaps, this had resulted to low ranking score.

\section{Conclusion and recommendation}

The results of the study suggest that scenic beauty is evidenced in several ecological landscapes of Fraser's Hill; e.g. lake and waterfall. However, ecosystem that experienced significant human intervention may receive scenic rejection. This is true in the ecosystem of waterfall and the land use of golf course and open space (themed garden). Findings also show that scenic value can be an indicator to determine healthy ecosystems of the hill station. For instance, more 
naturalness of a landscape would result to high preferences for scenic beauty. On the broader perspective, the results also indicate that natural and manmade elements can complement each other as long as the ecological value of a landscape is sustained. Besides that, the architectural heritage of Fraser's Hill is significant, due to its scenic, tourism and historical implications. The initial insight further implicates the local authorities to consider implementing sustainable landscape management practices. Importantly, the results may provide significant information to the tourism industry or the state of Pahang, since scenic beauty, good ecology and architectural heritage have economic importance. In conclusion, the results suggest that scenic beauty can be an indicator to identify healthy ecosystems of highland environment. The following is several recommendations proposed to sustain the ecological landscapes of Fraser's Hill:

i) To minimise human intrusion, so that, several important ecological attributes such as hilly landform, fresh water elements and lush of natural forest would be preserved at certain percentage. These are the attributes found to provide good implication to scenic beauty of Fraser's Hill. Here, the threat to healthy ecosystem is developments. Further, healthy ecosystems may be preserved by controlling the number of tourists' visitations. This idea has been successful implemented in the West.

ii) To preserve and sustain the architectural heritage of Fraser's Hill, which is directed to its colonial buildings. Perhaps, the local authority should enforce a policy that stresses on the application of coding system (e.g. colour, form, and design motifs); any structure erected on the highland should be parallel to its architectural heritage.

iii) To apply scenic as the indicator to sustain high ecological highland landscapes and perhaps, to spread its application to others highland ecosystems in future.

\section{References}

[1] de Groot, R. S., Alkemade, R., Braat, L., Hein, L., \& Willemen, L., Challenges in integrating the concept of ecosystem services and values in landscape planning, management and decision making. Ecological Complexity, pp. 260-272, 2010.

[2] Bell, S., The Aesthetics of the Landscape: The Nature of aesthetics. In: Landscape, Pattern, Perception and Process, New Fetter Lane London: E \& FN Spon, pp. 81-86, 1999.

[3] Daniel, T.C. and Boster, R.S., Measuring Landscape aesthetics: The Scenic Beauty Estimation Method. USDA Forest Service Research Paper RM-167. Rocky Mountain Forest and Range Experiment Station, Fort Collins, Colorado, 1976.

[4] Daniel, T.C., Whither Scenic Beauty? Visual Landscape Quality Assessment in the $21^{\text {st }}$ century. 1(4), pp. 267-281, 2001.

[5] Jamilah. O., and Nur Syazwani, R., Whether Perception or Expert Paradigm? Assessing Scenic Beauty of Nature Based Landscape. 
International Journal for Research in Emerging Science and Technology, 1(5), pp. 36-43, 2014.

[6] Gobster, P.H., Nassauer, J.I., Daniel, T.C., and Fry, G., The shared landscape: what does aesthetics have to do with ecology? Vol. 22, pp. 959972, 2007.

[7] Kaplan, R., and Kaplan, S., The experience of nature. A psychological perspective. New York: Cambridge University Press, 1989.

[8] Odum, E., The Scope of Ecology. In: Ecology, The link between the natural and the social sciences. New York: University of Georgia, pp. 170-180, 1975.

[9] Anderson, L.M., Landscape Aesthetic - A Handbook for Scenery Management. The Visual Management System, 1(2), p. 33, 1995.

[10] Galliano, S.J., and Loeffler, G.M., Scenery Assessment: Scenic Beauty at the Ecoregion Scale. Report PNW-GTR-472. Portland, Oregon: Department of Agriculture, Forest Service, Pacific Northwest Research Station, 2000.

[11] Kiew, R., Development and Conservation of Penang Hill. In: R.P. Lim, and Lee Su Win (Eds.), Hill Development Proceedings of the Seminar Kuala Lumpur: United Selangor Press, pp. 33-39, 1992.

[12] Knopf, A.A., Knopf Guides: Singapore and Malaysia. New York: Alfred A. Knopf, Inc., pp. 220-221, 1996. 